\title{
Franklin Institute.
}

\author{
[Proceedings of the stated mecting held Wednesday, Nozember 17, 1897.]
}

HAL, OF THE FRANKLIN INSTITU'TE, Philadel,Phia, November 17,1897 .

Mr. Johr BIRkinbine, President, in the chair.

Present, ro2 members and visitors.

Additions to membership since last report, 25 .

The President made some remarks on the approaching completion of the work of stacking the library in the newly arranged fire-proof quarters that have been prepared for the purpose, and urged upon the nuembers the desirability of bringing the change to the notice of their friends.

Mr. Chauncey N. Dutton, of New York, was introduced by the President as the first speaker of the evening. Mr. Dutton gave a description, illustrated with the aid of a working model and numerous detail drawings, of a pneumatic lock for canals, involving a system and apparatus of his invention.

The remarks of the speaker were devoted specially to a lock of this character ( $62 \mathrm{~L} / 2$ feet lift) which he had designed for Lockport, New York, and which had been approved by the Canal Commissioners of the State of New York. The subject evoked a lengthy discussion, participated in by Messrs. E. A. Scott, Spencer Fullerton, G. M. Eldridge, Joseph Richards, Theo. D. Rand, the President and Mr. Dutton.

On Mr. Fullerton's motion, duly seconded, the subject of the paper was referred to the Committee on Science and the Arts for investigation and report.

Mr. Wm. C. Henderson, by invitation, presented a communication "On Kryolith, its Mining, Preparation and Utilization." The communication was illustrated with the aid of a series of lantern slides.

The Secretary called attention to a method of determining the density of smoke from furnace chimneys, devised by Dr. Ringelman, and illustrated the system with the aid of a lantern slide.

Adjourned.

Wm. H. WaHI, Secretary.

\section{COMMITTEE ON SCIENCE AND THE ARTS.}

[Abstract of proceedings of the stated meeting held Nozember 3, 1897.]

MR. JAMES CHRISTE in the chair.

Reports on the following subjects passed first reading :

Perpetual Power with Manageable Air-Ship, J. A. Klefler, Philadelphia The Duplication of the Cube, Charles Morrell, Chicago, Ill.

Investigations with the Electric Furnace, Henri Moissan, laris, France. Improvements in Tidal Powers, Ernst Markmann, Philadelphia.

"Franklin Medal" Foundation (Institute). 